\title{
The Application of Psychological Factors \\ in the Experience Product Design
}

\author{
Haixia Wang, Chang Xiao \& Dan Liu \\ College of Art and Appareluages, Tianjin Polytechnic University \\ 399 Bin Shui Xi Street, Tianjin 300387, China \\ Tel: 86-10-8395-0255Ｅ-mail: wanghaixia_1227@163.com
}

\begin{abstract}
Since 1990s more and more enterprises have realized the importance of commercial rules such as "customer-centered" or "market-targeted", the experience economy has turned up recently. This new time has triggered a great revolution in human history of design: the experience design has arisen. In this context, the following paper aims to discuss the application and importance of psychological factors in experience design and how to use the psychological and related knowledge to get rid of the market predicament of product homogenization, so as to upgrade and develop the traditional product.
\end{abstract}

Keywords: Experience economy, Experience design, Psychology, Psychological factors

\section{Preface}

The British economist and philosopher mill said: "for human time is important than money. The good life is full of freedom, Engaged in the activities of interest, to meet the basic needs of the responsibility that limit life. Human beings should use limited time to think of the problems which have value, Reading valuable books, writing poems, singing, appreciating the art, learning a new language, walking in the park, to see sunrise and sunset on the beach, or to listen the birds singing......." (Liu Qunwang, Wang Yumin, 2005)

In the 20th century, for human beings this fantasy about future sounds unreachable and so far from our real life! However, since 1990s people have got rid of the regular work time, the core family has gradually collapsed, DIY movement has flourished for the moment, all these have just fulfilled the prophecy by Alvin Toffler who is American future historian! We can say that the human beings now have more freedom to a large extent, They have entered a new era-The Experimental Economy era!

\section{The meaning and characteristic of experience economy and design}

In B·Joseph Pine II and James H·Gilmores' book: "The Experimental Economy", the authors have described it as: "Here consumption is just process, consumer is its product. When the process comes to end, experience memory will be kept in the consumers mind for a long time. They are willing to pay for the experience, just because it is a nice, scarce, unique, unduplicated, nontransferable and fleeting thing, every moment is exclusive." (B. Joseph Pine, James H. Gilmore, 2002) It is clear that the character of experimental economy is emphasizing the consumer's feel and their initiative. By the words "feeling" and "experience" we can see the experimental economy is emphasized in consumer's satisfaction in the process of consumption. In the experimental economy, the rapid development of science and technology makes the realization of the product's function much easier, the traditional function innovation is no longer a businessman's main selling point, the product's homogeneity phenomenon is seriously. So If businessmen want to gain an advantage in this competition, The only shortcut is to pay high attention and excavate consumer's psychological factors deeply in the design, they can survive only by this way. In this case, as requested by society, the "experimental design" (Mu Feng, Zhu Junjie, 2008) has turned into the strongest note of all design styles! Those psychological factors involved have become the soul and melody of the design.

The Industrial design is a discipline which always ready to solve problems, we all know that at the beginning of the 20th century Germany "Bauhaus" (Wang Shouzhi, 1987) laid the foundation of modern industrial design discipline. It had established the function design style, and its influence has been alive until today. However, along with the development of modern disciplines, many new subjects are regularly coming out. Such as: Modern Psychology, 
Marketing, Ergonomics and so on. Various disciplines crossover fusion has expanded industrial design with its connotation and denotation. Modern product design has become a multidisciplinary subject, the concept of product has a broader definition, it has expanded to include product, service, movement, information, knowledge, property and so on which can be market-oriented, in this era the successful product definition also has taken subtle change, the successful products are those which can capture the consumers emotional needs, touch the inner potential demand of users, thus arouse consumers purchasing desire.

\section{The psychological factors and its importance in experience design}

While how to make the product more emotional in this new economic system? If we only do some facial work, hope for win consumer's favor by changing the product shape and its exterior decoration, I think that is impossible. This will get into another trouble, just like the American "planned obsolescence" (Wang Shouzhi, 2002), and be bound to case a waste of resources! So we must analyze the key role of psychological factors in the product design according to the present economic form. The product by which use the psychological factors is the one really satisfy consumers' demand, this product can touch the consumers heart and soul, thus arouse their purchasing desire. Not only that, I think only such products can be lasting and classical ones. Take the top brands throughout the world for example, they all brand experience and the user's experience design ability as the core competitiveness. Now we give some existing successful examples, it is observed that they all verified this theory.

As Europe's leading design Italy ALESSI (ALESSI'S design philosophy) means art and taste, it always pay attention to the original taste and life, ALESSI'S special character is its develop direction just in conformance with the request of nowadays industry, at the same time they pay attention to add human's spiritual power to products. Many of them possess irresistibly appetency, they are the typical representative of good use of the psychological factors in design.

Italy ALESSI, the DreamWorks, has many international famous designers, their classical products are the successful application of psychology factors, they are easily sympathized with the customers.

The following pictures are some ALESSI'S classical household goods and kitchen tackle:

Figure.1-Figure.2 are some ALESSI'S kitchen tackle, undoubtedly, facing these goods do evoke a hearty laugh. Because they are so lovely, humorous, rebellious and screaming! They can jog your memory, make you feel it is your own personal items, they are unique, and you are inclined to bag it. They are just the results of clever apply psychological factors in design projects.

IKEA (Chen Guang, 2005), as the world's famous brand, is one of a few dazzling commercial wonders in 20th century. It aims to build better life for the masses, its business philosophy is to provide variety, beautiful, practical and affordable household articles. The source of its design is derived from humanistic ideas, functionalist methods, traditional crafts with modern technology and peaceful nature of the modern lifestyle in boreal Europe. Among these the most important is, it builds a new kind of consumption pattern-Experimental Consumption, it has adopted the modular design thought of DIY, which fully mobilize the enthusiasm of the consumer, thus induce the users to exploit their creativity to participate in the redesign process actively.

It is said in Modern Psychology: "Everyone has the potential of creativity, only in the process of creation, can their natural instinct of interest and requirement be satisfied, under such conditions, their personality can fully display, their thoughts get free and emotional satisfaction." (Jung,C.G.( Swiss), Trans. Cheng Qiong and Wang Zuohong, 1991) IKEA'S success is just the result of fully use of psychological factors, its successful story just prove the importance of the usage of psychological factors in design.

In IKEA, you can enjoy your creative, assemble different products and build your small and warm home, the following picture (Figure3) shows some assemble styles:

Another example is the modern adult toys market which has the mental compensation effect: for modernist there is too much pressure at work and study, their life is always monotonous. These adult toys let a person fondle admiringly for their plain design, people in the play can relieve fatigue, release pressure and regulate their emotions, for most important they meet the modernists inner desire who want to avoid rip-roaring city, return to their childhoods. These toys are not like the children's, which are colorful, rich voice, simple operation, they are not depend on these characters but on exquisitely made, simple, easy, beneficial wisdom, creative, and funny to attract people's attention. The following Figure4 is a new kind of adult toys which is made of rubber, they can get all of your emotions out when you are in a bad mood.

There are many such examples, such as the Apple and Philips's experimental products and so on. Each one is a classic, designers use their talent to surprise the consumer, and all these products are collected by many fans.

To sum up, those classical products are not only with luxuriant appearance, because shape innovation is most likely to be followed by others, but the soul of product is not easy to be copied! The selling point of experimental products is its psychological touch function, only by adding psychological factors into product can make it eternal, such merchandise can capture and hold the consumers sight at the first time. 


\section{The design methodology based on the experience economy}

Then how to use psychological factors to success in the product experimental design? To some extent, it is a design methodology, its importance seems to be a self-evident statement. The correct methodology is the key to success, so it is necessary to comprehensive use of psychology, marketing knowledge to summarizing the principle.

The next we make a further research from psychological factors, summarize some psychological principles of the product experimental design. Considered of my limited ability, mistake is inevitable. So there is a long way to explore and perfect, in order to make a better guide for design practice.

1) Comprehensive use various senses, consciousness, make the products more friendly to consumers-- this is the foundation.

2) make use of the "group psychology" and "association psychology", choose stars as celebrity spokespeople to increase the products additional psychological value.

3) To arouse the consumers past wonderful memories, make the products more "plot" and "story".

4) understanding the consumers original psychology of participate in creating, leave certain space in product design, let customers take part in redesign, they may feel good in the process.

5) excavating the consumers' potential perception of his psychological needs - this is the highest ideal state

According to consuming psychology (Xu Ping, 2005): the relation of need, motivation and behavior is:

Need $\stackrel{\text { Stimulate }}{\longrightarrow}$ Motivation $\stackrel{\text { Drive }}{\longrightarrow}$ Behavior $\stackrel{\text { Achieve }}{\longrightarrow} \begin{gathered}\text { Meet the requirements } \\ \text { Target }\end{gathered}$ Action to end

Here we can see the demand is the first motive of consumer's behavior. So design is related to a kind of psychological emotional first, then it is related with technology and materials.

\section{Conclusion}

To sum up, modern product experimental design is the system of planning and integrated design, its starting point not confined to the function, or shape elements, but includes all the elements the customers valued. Among others, the psychological factors are the main factors. Because the "experience" is itself a psychology vocabulary, its characters can be summarized as "flexibility, emotion blends and then creation" (Min Zongtao, Quan Lixia, 2003) so psychological factors are the soul of experimental product. Just as "the hierarchy theory of needs" (Abraham Maslow's Van (US) the 3rd edition, 2007) which was proposed by American humanism psychologist Maslow in the 1940s, the experimental product design is just the new product of economy, in which human have step over their physiological basis and safety needs towards higher psychological ones.

In the experimental economy era, how to stimulate the economy and looking for a new economic growing point is the most severely problem we have faced. Especially in recent global economic crisis, how to upgrade and develop our traditional products is the shortcut for our economic recovery. Therefore, have a deep research on the psychological factors of experimental design is our urgent task. Psychological factors should be better applied to the innovation of the product design, so as to use these methods to guide our design practice. Making the products more emotional, and then cultivating the consumers' loyalty, also is more advantageous to the construction of our economical society.

\section{References}

Abraham Maslow's Van. (2007). Trans. Xu, Jinsheng. Motivation and Personality (the 3rd edition). Beijing: China Renmin University Press, April.

ALESSI's design philosophy. [Online] Available: www.whodesign.com.cn.

B. Joseph Pine \& James H. Gilmore. (2002). The Experience Design. Beijing: Mechanical Industry Press, May.

Chen, Guang. (2005). IKEA's Home Furnishing strategies. Guangdong: Guangdong Southern Daily Press, May.

Jung,C.G.. (1991). Trans. Cheng, Qiong and Wang, Zuohong. The Theory and Practice of Analytical Psychology. Beijing: The Joint Publishing Company Ltd., October.

Liu, Qunwang \& Wang, Yumin. (2003). The New Era of Consumption. The Experience Design, Vol. 8, No. 3.

Min, Zongtao \& Quan, Lixia. (2003).Experience: an economics decipherment. The Economists, Vol. 6.

$\mathrm{Mu}$, Feng \& Zhu, Junjie. (2008). Based on the user's experience of product design system. Packaging Engineering, Vol. 29, No. 3.

Wang, Shouzhi. (1987). The history of industrial design. Shanghai: Shanghai People's Fine Arts Publishing House, May.

Wang, Shouzhi. (2002). The modern history of design. Beijing: China Youth Press, September. 
Xu, Ping. (2005). Consumer psychology tutorial (the 2nd edition). Shanghai: Shanghai finance and economics university press.

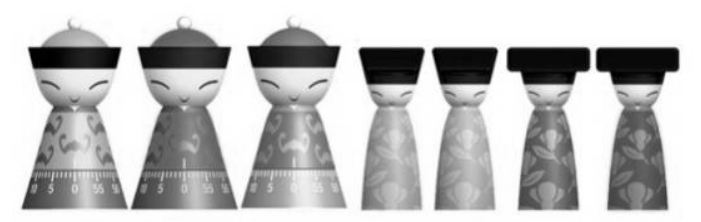

Figure 1. A Cruet Design for ALESSI: China Style

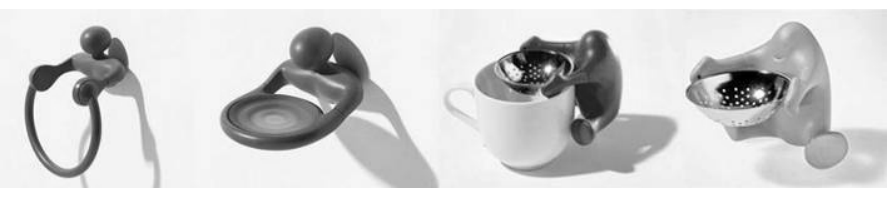

Figure 2. Kitchen Tackles of ALESSI

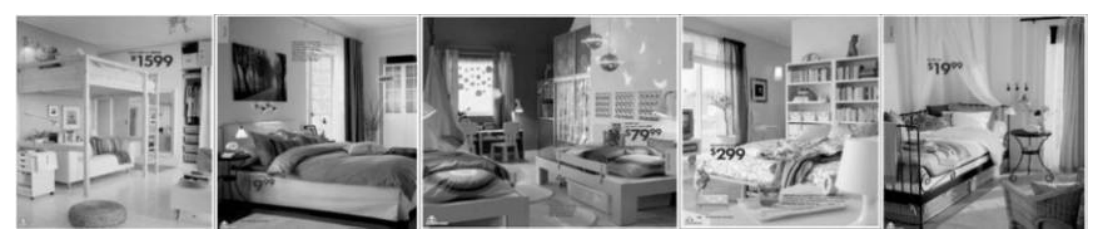

Figure 3. Fully Exert Your Creative Everyone Can Be Designer
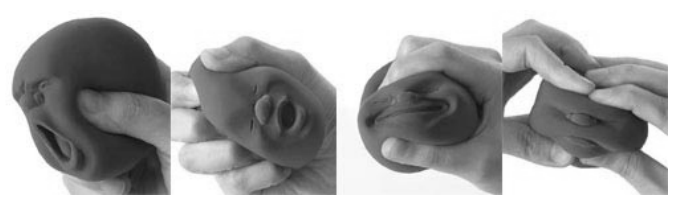

Figure 4. A Rubber Ball Named "Wan Yan A Gu Da" 